\title{
Saias e blusas: invenções para aprender a multiplicar com a Matemática Moderna
}

\author{
Skirts and blouses: inventions to learn how to multiply \\ with Modern Mathematics
}

\section{Faldas y blusas: invenciones para aprender a multiplicarse con la Matemática Moderna}

\author{
ElisABETE ZARDO BÚRIGO ${ }^{1}$ \\ NÍCOLAS GIOVANI DA ROSA (י) ${ }^{1}$ \\ MaYARA Becker OliveIRA DA SIlva ${ }^{1}$ \\ ${ }^{1}$ Universidade Federal do Rio Grande do Sul, Porto Alegre, RS, Brasil.
}

\begin{abstract}
RESUMO
O artigo apresenta uma investigação sobre uma experiência de inovação de ensino de matemática registrada em um caderno de uma aluna que frequentou o segundo ano do curso primário do Instituto de Educação General Flores da Cunha, na cidade de Porto Alegre, no ano de 1968. Trata-se de uma abordagem da multiplicação inspirada no conceito de produto cartesiano de conjuntos e orientada para o que é denominado, atualmente, pensamento combinatório. A instituição, dedicada à formação de professores primários, ofereceu um Curso de Didática da Matemática Moderna na Escola Primária desde 1966. Por meio do cruzamento de fontes diversas, a pesquisa identifica as conexões entre a experiência registrada no caderno, os estudos promovidos no Curso e as publicações de autores engajados no movimento da Matemática Moderna. Também são tecidas considerações sobre o currículo praticado naquela escola, sobre o poder criativo da cultura escolar e sobre as ressonâncias da Matemática Moderna nas produções correntes sobre o ensino de Matemática para os anos iniciais da escolarização.
\end{abstract}

Palavras-chave: História da Educação. Acervos escolares. Ensino primário. Formação de professores. Pensamento combinatório.

\begin{abstract}
The article presents an investigation about an innovative experience of mathematics teaching registered in a notebook of a student who attended the second year of the primary school of the Institute of Education General Flores da Cunha in the town of Porto Alegre in the year 1968. It is an approach of multiplication inspired by the cartesian product of sets concept and oriented to what is currently termed combinatorial thinking. The institution, dedicated to the training of primary teachers, offered a Course on Modern Mathematics Didactics in the Primary School since 1966. Through the cross-referencing of several sources, the research identifies connections between the experience recorded in the notebook, studies promoted in the Course and publications of authors engaged in the Modern Mathematics movement. Considerations are also made on the curriculum practiced in that school, on the creative power of the school culture and on the resonances of Modern Mathematics in the current productions on the teaching of Mathematics for the early years of the schooling.
\end{abstract}

Keywords: History of Education. School collections. Elementary school. Teacher training. Combinatorial thinking.

\section{RESUMEN}

El artículo presenta una investigación sobre una experiencia de innovación de enseñanza de matemáticas registrada en un cuaderno de una alumna que frecuentó el segundo año del curso primario del Instituto de Educación General Flores da Cunha en la ciudad de Porto Alegre en el año 1968. Se trata de un abordaje de la multiplicación inspirada en el concepto de producto cartesiano de conjuntos y orientado a lo que se denomina actualmente pensamiento combinatorio. La institución, dedicada a la formación de profesores primarios, ofrecía el Curso de Didáctica de la Matemática Moderna en la Escuela Primaria desde 1966. Por medio del cruce de fuentes diversas, la investigación identifica conexiones entre la experiencia registrada en el cuaderno, estudios promovidos en y publicaciones de autores comprometidos en el movimiento de la Matemática Moderna. También se tejen consideraciones sobre el currículo practicado en aquella escuela, sobre el poder creativo de la cultura escolar y sobre las resonancias de la Matemática Moderna en las producciones corrientes sobre la enseñanza de Matemáticas para los años iniciales de la escolarización. Palabras clave: Historia de la Educación. Acervos escolares. Enseñanza primaria. Formación de profesores. Pensamiento combinatorio. 


\section{INTRODUÇÃo}

O movimento da Matemática Moderna, transcorrido no Brasil entre os anos 1960 e 1970, tem sido objeto de múltiplas investigações, que iluminam facetas variadas dos processos de produção e circulação de propostas de inovação do ensino de matemática na escola primária e secundária, naqueles tempos ${ }^{1}$. Menos abundantes são os estudos que tomam por objeto os impactos do movimento sobre a matemática ensinada nas escolas e as marcas dessa experiência nos currículos atualmente praticados ${ }^{2}$. Nesse contexto, as avaliações de um "fracasso" da Matemática Moderna, que circularam nos anos 1970 e 1980 pelas vozes de autores renomados como Kline (1976), tendem a se amalgamar com reminiscências de professores daquele tempo em uma representação ainda bastante disseminada de que as propostas do movimento teriam sido esquecidas ou abandonadas, após o seu refluxo.

$\mathrm{O}$ uso de cadernos escolares como fontes pode dar uma contribuição importante para as investigações sobre os efeitos de movimentos e reformas sobre os currículos escolares, uma vez que são ricos em registros das práticas de sala de aula (VIÑAO, 2008; LEME DA SILVA; VALENTE, 2009). Este artigo trata de uma investigação provocada por um registro de atividade de estudante, que encontramos em um caderno escolar do ano de 1968, muito assemelhado a um material utilizado em atividades de formação de professores para a Matemática Moderna. O caderno pertenceu a uma estudante do segundo ano do curso primário do Instituto de Educação General Flores da Cunha (GROSS, 1968) e o curso de formação ocorreu na mesma instituição.

A partir desses vestígios, buscamos outras fontes, com o intuito de identificar conexões entre as aulas de matemática daquela turma do segundo ano primário e as movimentações de renovação do ensino de matemática em curso, naquela época, no Rio Grande do Sul, na cidade de Porto Alegre e, mais precisamente, no Instituto de Educação.

O cruzamento do caderno com vários outros documentos permite identificar, naquela página do caderno, marcas do movimento da Matemática Moderna. O exercício tratava de combinar saias e blusas, um traje comum nos anos 1960 e, especialmente, um traje de

\footnotetext{
1 Pode-se considerar como pioneiro o trabalho de d'Ambrosio (1987), recentemente publicado em português (D'AMBROSIO, 2017). Produto do projeto de cooperação internacional CAPES/GRICES “A Matemática Moderna nas escolas do Brasil e de Portugal: estudos históricos comparativos", a coletânea de Oliveira, Leme da Silva e Valente (2011) apresenta uma reflexão sobre as pesquisas realizadas em torno da temática até 2010 . A continuidade das investigações, inspiradas por novas questões e novas fontes, é testemunhada por artigos publicados neste dossiê.

2 Vale mencionar a questão formulada por Sanchez $(2009$, p. 8): "Mas afinal o que aconteceu? Como saber o que significou a Matemática Moderna no processo de transformação do ensino?".
}

uso das normalistas. A presença de saias e blusas em livros didáticos e em documentos curriculares recentes, como evocação do pensamento combinatório, nos permite, ademais, perceber aí uma marca permanente do movimento modernizador.

No texto que segue, apresentamos o percurso da pesquisa, acompanhado de algumas reflexões sobre os processos pelos quais são constituídos e modificados os currículos escolares.

\section{APRENDENDO A MULTIPLICAR COM SAIAS E BLUSAS}

Desde 2016, estamos engajados em uma campanha de coleta e digitalização de cadernos escolares com aulas de Matemática, para a constituição de uma coleção digital no âmbito do Repositório Institucional da Universidade Federal de Santa Catarina (UFSC) ${ }^{3}$. Dentre os cadernos coletados no Rio Grande do Sul, está o "Diário de aulas" produzido por Cristiane Gross, quando frequentava o segundo ano do curso primário no Instituto de Educação General Flores da Cunha, em 1968.

Durante a digitalização do caderno, deparamo-nos com um registro intitulado "Trabalho de Matemática", datado de 8 de agosto. O primeiro exercício, exibido na Figura 1, tem como enunciado a pergunta "Tenho 8 blusas e 2 saias. Quantos trajes poderei formar?".

Figura 1 - Primeira atividade do "Trabalho de Matemática", de 8 de agosto

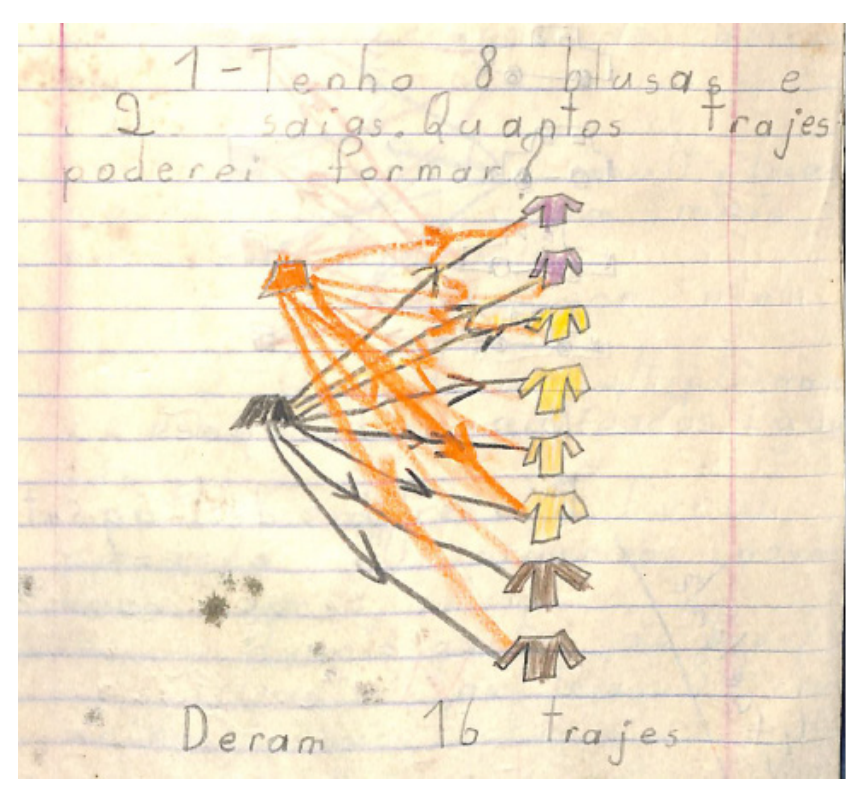

Fonte: Gross (1968)

\footnotetext{
3 A subcoleção "Cadernos Escolares" da coleção "História da Educação Matemática", do Repositório Institucional da UFSC, está disponível online em: https://repositorio.ufsc.br/handle/ 123456789/160300.
} 
Entre a pergunta e a resposta - "Deram 16 trajes" temos a imagem de um gráfico em que cada uma de duas saias (uma laranja e uma preta) está ligada a cada uma de 8 blusas (duas lilases, quatro amarelas e duas marrons) por uma flecha.

Viñao $(2008$, p. 25) nos adverte de que, pelos cadernos, não podemos saber tudo o que se passou em uma sala de aula:

Nem tudo está nos cadernos. Eles silenciam, não dizem nada sobre as intervenções orais ou gestuais do professor e dos alunos, sobre seu peso e o modo como ocorrem e se manifestam, sobre o ambiente ou clima da sala de aula, sobre as atividades que não deixam pistas escritas ou de outro tipo, como os exercícios de leitura (a leitura em voz alta, por exemplo) e todo o mundo do oral.

No caso em tela, não sabemos se a estudante, autora dos registros inscritos naquele caderno, escolheu as cores e os modelos das saias e blusas que desenhou, ou se seguiu alguma instrução da professora. Mas, daquilo que sabemos sobre a organização do ensino primário e o uso de cadernos, no Brasil, na segunda metade do século XX, e considerando o padrão dos registros ali contidos, incluídas as anotações de correção, podemos inferir que copiar e resolver o exercício era uma atividade atribuída a toda a turma. Tratava-se de um modo de aprender e exercitar a multiplicação. Mais ainda: considerando-se que aprender a resolver problemas aritméticos segundo padrões ensinados - incluindo a organização gráfica dos elementos da solução - era um elemento importante da cultura da escola primária dos anos 1960, podemos supor que o caminho adotado na resolução - desenhar saias em uma coluna e blusas em outra, ligar saias e blusas por flechas com a mesma cor das saias - seguiu um padrão indicado pela professora.

O que nos surpreendeu nesse registro de um exercício?

$\mathrm{O}$ uso de imagens para o ensino da multiplicação, na escola primária, não é uma novidade do final dos anos 1960.

$\mathrm{Na}$ segunda metade do século XIX, os livros de Antonio Trajano, inspirados no método intuitivo, já apresentavam imagens com representações de operações aritméticas. Como explica Oliveira (2017, p. 136), as ilustrações nos livros de Trajano "têm a função de induzir o aluno na construção do saber". A Figura 2 apresenta uma imagem extraída da $68^{\underline{a}}$ edição da Arithmetica Elementar Illustrada, com data de publicação estimada entre 1900 e 1910. A imagem cumpre a dupla função de ilustrar o problema - uma situação em que objetos aparecem agrupados em quantidades iguais - e possibilitar a obtenção da solução, pela contagem desses mesmos objetos.
Figura 2 - Problema sobre cerejas, cachos e galhos, introdutório à multiplicação

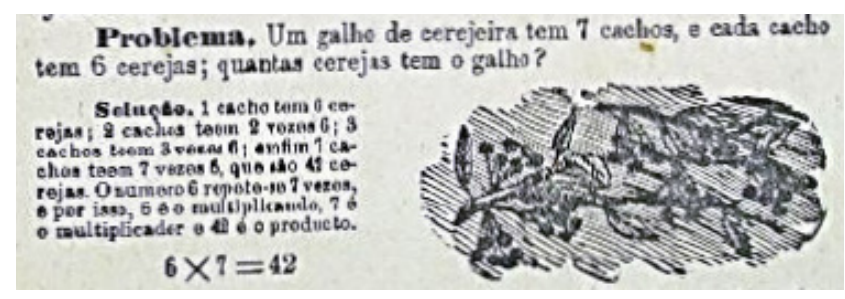

Fonte: Trajano ([190-?], p. 27).

A circulação das ideias da Escola Nova, que enfatizam a ação dos alunos, em oposição à memorização e como alternativa aos métodos considerados tradicionais (LEME DA SILVA; VALENTE, 2013), suscita novos usos das imagens, como o de inspirar a redação de problemas pelos estudantes. A Figura 3 mostra uma sugestão apresentada aos professores por Irene de Albuquerque (1951), com o objetivo de substituir o estudo da tabuada.

Figura 3 - Item das "Sugestões práticas" apresentadas aos professores

3 - Inventar um problema de adiçăo (subtraçăo, multiplicaçäo ou divisäo) com um desenho dedo, e resolvo-lo.

i. $r_{2}$

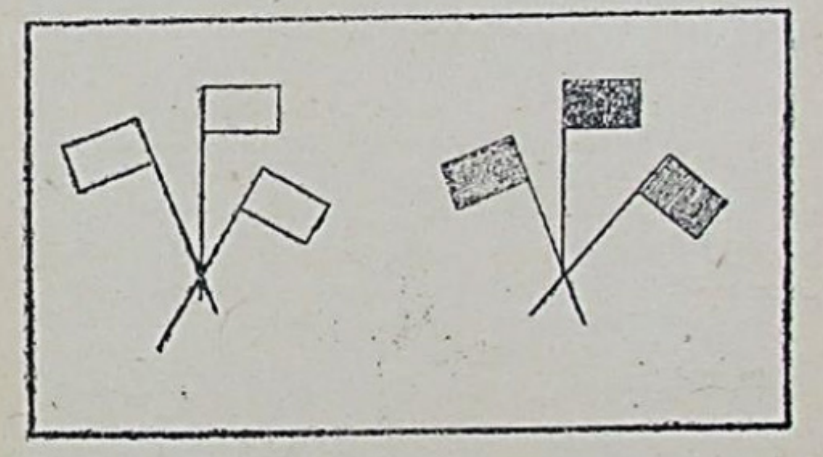

Fonte: Albuquerque (1951, p. 95)

Sabemos, também, pelo depoimento de ex-alunas do Instituto de Educação, que nos anos 1950 e 1960 as normalistas aprendiam a ensinar as operações com o apoio de ilustrações e de objetos manipuláveis, como feijões e tampinhas de garrafas (BÚRIGO; PEIXOTO, 2018).

Considerando o uso já costumeiro de imagens para ilustrar e, inclusive, auxiliar no entendimento da multiplicação, é possível, contudo, identificar traços de inovação na abordagem da multiplicação registrada no caderno de Cristiane Gross (1968). Em primeiro lugar, a ideia de reunir agrupamentos com o mesmo número de objetos, do mesmo tipo, reiterada nos programas, manuais e artigos pedagógicos, é substituída pela ideia de combinar elementos de conjuntos diferentes. Em linguagem contemporânea, teríamos aí uma abordagem do 
pensamento combinatório, ou do princípio multiplicativo. A solução para o problema não é obtida como uma soma de parcelas iguais. A segunda novidade é o uso de flechas para representar graficamente as combinações. Diferente da solução sugerida por imagens como a da Figura 3, a resposta ao problema não é dada pela contagem dos objetos (saias e/ou blusas), mas pela contagem das flechas - um elemento gráfico acrescentado à representação da situação - que representam as combinações possíveis.

A mesma ideia reaparece no segundo exercício do "Trabalho de Matemática" do caderno: "Com 4 automóveis e 4 latas de tintas de cores diferentes, quantas combinações faremos?" (GROSS, 1968). Como o exercício anterior, esse é resolvido com um desenho: cada um de 4 automóveis é ligado a cada uma de 4 latas de tintas, por flechas coloridas. Ao final, consta a resposta "16 combinações".

Em ambos os casos, há uma evocação da ideia de produto cartesiano entre dois conjuntos. Pensar em todas as combinações possíveis de saias e blusas equivale a tomar todos os pares ordenados distintos que podem ser formados tendo como primeiro elemento uma saia e como segundo elemento uma blusa. O mesmo vale para automóveis e latas de tinta. O número de pares ordenados - isto é, o cardinal do produto cartesiano - é o produto do cardinal do primeiro conjunto (saias ou automóveis) pelo cardinal do segundo (blusas ou latas de tinta).

No caderno, a expressão "produto cartesiano" não é mencionada. Mas o uso de flechas para representar as combinações sugere que, de algum modo, a ideia de "relação" - um tema valorizado pela Matemática Moderna - estava implicada na intenção da professora ou do autor ou autora daquela atividade. Mas qual ou quais teriam sido as fontes inspiradoras da atividade ou dessa intenção pedagógica?

A abordagem das operações aritméticas a partir das operações entre conjuntos é um traço reconhecido do movimento modernizador, ou das vertentes da Matemática Moderna que foram mais amplamente divulgadas no Brasil. Mas a ideia da multiplicação como produto cartesiano não está presente em algumas produções do movimento que tiveram ampla circulação. Por exemplo, não está presente nas primeiras edições da coleção Matemática - Curso Moderno para cursos ginasiais, de Sangiorgi (1964), que circulou em todo o País, ou nas coleções de Thofehrn e Cunha (1968), que circularam no Rio Grande do Sul.

\section{APRENDENDO A MULTIPLICAR COM A MATEMÁtica Moderna}

Saias e blusas, curiosamente, foram também encontradas em um repositório de documentos e materiais didáticos, em cuja organização estávamos - e estamos - também engajados: o acervo do Laboratório de Matemática do mesmo Instituto de Educação General Flores da Cunha (LM/IE) $)^{4}$. Em um envelope contendo fichas de atividades, havia figuras desenhadas em papel acartonado colorido e recortadas, de modo que pudessem ser dispostas e combinadas de modos variados, como no exemplo da Figura 4.

Figura 4 - Peças recortadas para composição de trajes

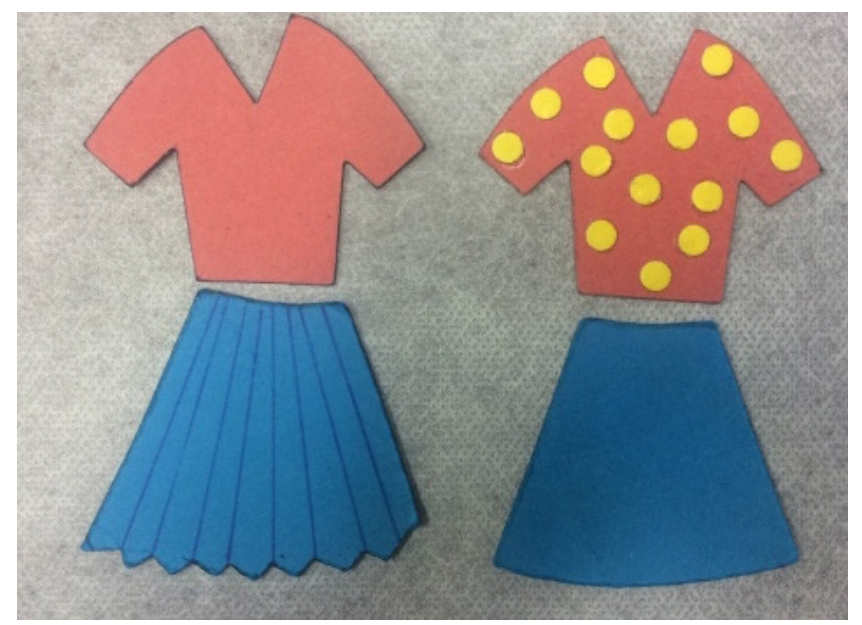

Fonte: Item 1031 do acervo LM/IE. Uma das fichas do envelope trazia inscrito o enunciado: "Uma menina tem duas saias, uma lisa e outra pregueada. Tem também duas blusas, uma lisa e outra com bolinhas. Quantos trajes diferentes ela pode formar?". Pode-se supor, então, que as figuras foram produzidas para a experimentação de possibilidades de composição de trajes, como caminho para a resposta à pergunta.

O cruzamento entre o caderno e o material didático nos fez atentar às prováveis conexões entre o ensino de matemática ministrado naquela turma do segundo ano primário e as atividades desenvolvidas no Laboratório de Matemática. O modo como o material foi cuidadosamente protegido e guardado sugere que a ficha e as figuras teriam sido usadas em planejamento de estágio ou em alguma disciplina ou curso de formação de professores oferecido pelo Instituto de Educação. Pois, de acordo com o Regulamento do Ensino Normal vigente, as classes do ensino primário deveriam se constituir em "campo de prática, orientação e experimentação pedagógica" (RIO GRANDE DO SUL, 1955, p.93). Em entrevista, Cristiane Gross (2018) confirmou que, nas aulas do curso primário, era comum a presença de uma observadora na sala de aula.

\footnotetext{
4 Desde o início das obras de restauro do prédio da instituição, em 2016, o acervo do Laboratório de Matemática do Instituto está sob os cuidados de equipe de pesquisadores da Universidade Federal do Rio Grande do Sul (UFRGS). A higienização, a produção de inventário e a organização dos materiais do acervo, bem como a produção deste artigo, são atividades do projeto de pesquisa "Estudar para ensinar: práticas e saberes matemáticos nas Escolas Normais do Rio Grande do Sul (1889 - 1970)", financiado por Chamada Universal do CNPq.
} 
Sabemos, de trabalhos anteriores, que propostas de modernização do ensino de matemática relacionadas à Teoria dos Conjuntos e às estruturas algébricas circularam no Instituto de Educação desde os anos 1950, por meio de palestras e cursos ministrados por professores da instituição e da Universidade Federal do Rio Grande do Sul (UFRGS), dentre os quais se destaca o nome de Joana de Oliveira Bender ${ }^{5}$ (BÚRIGO, 2010).

Bonfada (2018), a partir de relatórios encontrados no acervo do LM/IE, registra que, já em 1961, o Laboratório de Matemática contava com livros de autores engajados no movimento modernizador. A autora também apresenta registros da oferta do Curso de Didática da Matemática Moderna na Escola Primária, pelo Instituto de Educação, a partir de 1966, tendo como alunas professoras do curso primário e do Jardim de Infância do próprio Instituto. Conjecturamos, então, que calcular números de combinações de saias e blusas teria sido uma atividade planejada por participantes do Curso, aplicada ou replicada naquela turma do segundo ano do curso primário. Buscamos outros documentos, no acervo do Laboratório de Matemática e em outros repositórios, que pudessem auxiliar no refinamento dessa hipótese.

Encontramos uma discussão sobre a Matemática Moderna em uma ata de reunião de estudos das professoras de Didática, realizada em 16 de março de 1967:

Em que consiste a Matemática Moderna? Matemática Moderna não é apenas apresentação de novas técnicas de ensino. Aceitamos plenamente a opinião da professora Joana Bender para quem a Matemática Moderna é a reformulação e o enriquecimento de conteúdos (Teoria de Conjuntos e Teoria das Relações) e consequente apresentação que exige o aparecimento de novas Técnica, Terminologia e Simbolismo (Item 1316 do Acervo do LM/IE, p. 1).

Anexo à ata está o "Relatório do 1 $\mathrm{O}$ ano de atividades do curso" do Grupo 711, que incluiu 93 aulas da "Parte referente à fundamentação matemática", ministrada pela professora Esther Pillar Grossi ${ }^{6}$, duas aulas de Psicologia, ministradas pela professora Italia Faraco, e cinco aulas de Didática, ministradas pela professora Odila Barros

\footnotetext{
5 Joana de Oliveira Bender licenciou-se em Matemática em 1947 e foi professora da Faculdade de Filosofia da UFRGS desde os anos 1950. Seu engajamento no movimento da Matemática Moderna no Rio Grande do Sul, comentado por Búrigo (2010), ainda carece de investigação mais aprofundada.

${ }^{6}$ Esther Pillar Grossi foi protagonista do movimento da Matemática Moderna no Rio Grande do Sul, tendo sido uma das proponentes do já mencionado Curso de Didática da Matemática Moderna, fundadora e presidente do Grupo de Estudos em Ensino de Matemática de Porto Alegre (GEEMPA), criado em 1970, e coordenadora da experiência com classes-piloto iniciada em 1972, na região de Porto Alegre, em interlocução com Zoltan Dienes (FISCHER, 2006).
}

Xavier ${ }^{7}$. O Relatório menciona também que foram lidas as obras Os conjuntos e as operações com conjuntos e $A$ Matemática Moderna no ensino primário, de Zoltan Paul Dienes $^{8}$, o livro Os números para contar, de Irving Adler ${ }^{9}$, e o primeiro capítulo do livro Mathématique Moderne que, pelos detalhes mencionados, pode-se concluir ser a obra Mathématique moderne, mathématique vivante do matemático francês André Revuz ${ }^{10}$ (1963).

Anexo ao relatório, por sua vez, está o texto "Fundamentação matemática", que detalha os conteúdos abordados nessa parte do curso, agrupados como: Noção de Conjunto - primeiros conceitos; Introdução à Lógica Matemática; Propriedades das Relações; Conceito de Função; Cardinal; Relações no Conjunto dos Naturais. Esse último capítulo inclui o item "Operação multiplicação no Conjunto dos Naturais".

No texto, a multiplicação é, inicialmente, associada à união de conjuntos de mesmo cardinal. Em seguida, é associada à ideia de produto cartesiano, "onde um dos fatores é representado pelo cardinal do número de classes e o outro é representado pelo cardinal do número de elementos de cada classe e, o produto é igual ao cardinal do número de duplas" (Item 1316 do Acervo do LM/IE, p. 10).

\footnotetext{
Odila Barros Xavier ingressou como professora da então Escola Normal de Porto Alegre em 1936, na escola primária anexa. Em 1938, assumiu a Cadeira de Pedagogia do Curso Complementar. A partir de 1949, lecionou a disciplina de Metodologia da Matemática no Curso de Administradores Escolares. Em 1951, criou o Laboratório de Matemática e, no final da década, iniciou o Círculo de Estudos de Matemática no Instituto de Educação. Ao longo de sua trajetória, divulgou propostas e empreendeu ações em prol da renovação do ensino de matemática; em 1966, aposentou-se (DALCIN; BONFADA; RHEINHEIMER, 2018).

8 Zoltan Paul Dienes doutorou-se em Matemática pela Universidade de Londres, em 1939. Interessou-se pela psicologia da aprendizagem nos anos 1950 nos anos 1950 e diplomou-se em Psicologia. Em 1964, fundou o International Study Group for Mathematics Learning (ISGML), cujos encontros tinham por finalidade a discussão de processos de aprendizagem matemática, a formação de professores, a elaboração de currículos e o planejamento de ações concretas no ensino elementar. Educadores matemáticos brasileiros, dentre os quais Esther Grossi, participaram das sessões sul-americanas do ISGML (VALENTE, 2012). Os livros citados no Relatório estão entre os primeiros de uma vasta produção dedicada ao ensino.

${ }^{9}$ Irving Adler foi professor de matemática no ensino secundário, nos Estados Unidos, desde os anos 1930 até 1952, quando foi perseguido por sua atividade sindical e afastado do cargo. Publicou vários livros de divulgação científica para crianças e adolescentes, e alguns livros para adultos, dentre os quais New mathematics, em 1958, em que se identifica com o emergente movimento de modernização do ensino.

${ }^{10}$ André Revuz foi professor de matemática no ensino secundário e universitário na França. Defendeu tese em matemática em 1956, sob orientação de Gustave Choquet. Nos anos 1960, foi presidente da Association des Professeurs de Mathématiques de l'Enseignement Public (APMEP) e da Société Mathématique de France (SMF). Foi um membro ativo da Comissão Ministerial sobre o Ensino de Matemática (CEEM) criada em 1966, participando da reforma modernizadora do ensino de matemática no secundário e da criação dos Instituts de Recherche sur l'Enseignement des Mathématiques (IREM). No mesmo período foi membro do comitê executivo da Commission Internationale de l'Enseignement des Mathématiques (CIEM), de 1967 a 1970 (COLMEZ et al., 2010). A obra Mathématique moderne, mathématique vivante divulga ideias então debatidas na APMEP e na CIEAEM.
} 
Figura 5 - Fragmento do texto "Fundamentação matemática"

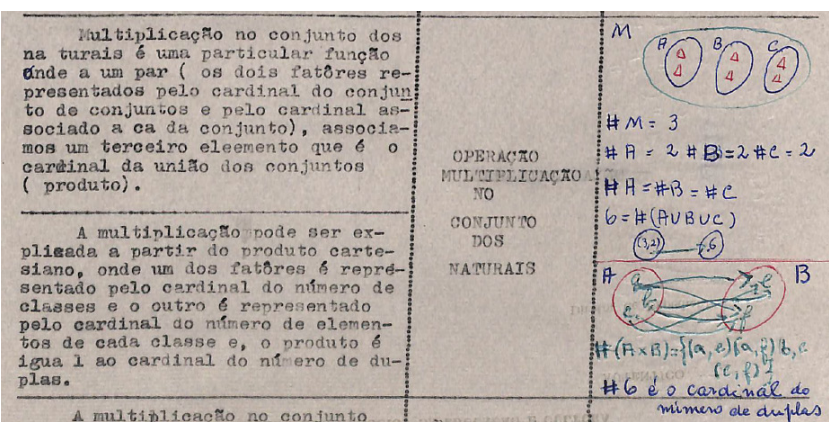

Fonte: Item 1316 do Acervo do LM/IE.

Na Figura 5, vemos os dois textos e os gráficos a eles associados, representando as duas abordagens da multiplicação. Ainda, após a apresentação desse item, constam "Considerações sobre conjunto universo": "O conjunto universo das relações é o produto cartesiano de todos os elementos do conjunto de partida com todos os elementos do conjunto de chegada (Conjunto de todas as possibilidades de duplas)" (Item 1316 do Acervo do LM/IE, p. 11).

O relatório do Curso indica, portanto, que a ideia de produto cartesiano era abordada nas aulas de Fundamentação Matemática; mais ainda, que a ideia de multiplicação poderia ser explicada como produto cartesiano e, ainda, que esse produto cartesiano poderia ser representado graficamente por um conjunto de flechas ligando cada um dos elementos de um conjunto de partida A a cada um dos elementos de um conjunto de chegada $\mathrm{B}$, sendo esses elementos representados por pontos associados a letras.

Quais teriam sido as referências para a abordagem da multiplicação como produto cartesiano, no Curso de Didática da Matemática Moderna?

Como comentado anteriormente, essa não era uma ideia disseminada de modo generalizado, nos textos de difusão da Matemática Moderna, nos anos 1960. Essa perspectiva não é explicitada, por exemplo, no livro Um programa moderno de matemática para o ensino secundário, elaborado em 1961 por um grupo de especialistas, a convite da Organização para a Cooperação e Desenvolvimento Econômico (OCDE), traduzido e publicado em 1965, no Brasil, pelo Grupo de Estudos do Ensino da Matematica (GEEM). Também não é mencionada na primeira publicação do GEEM, a coletânea Matemática moderna para o ensino secundário (GEEM, 1962).

Em escritos posteriores, Esther Grossi (2005, p. 12) afirma que os primeiros contatos com a Matemática Moderna foram "por meio de Lucienne Félix e, depois, com os blocos lógicos e as publicações de Zoltan Dienes, da mesma maneira que através dos livros de George Papy".
Mas a ideia de multiplicação como produto cartesiano não está presente na obra Mathématiques modernes $\cap$ enseignement élémentaire, de Lucienne Félix ${ }^{11}$ (1960), que integra o acervo do Laboratório de Matemática do IE. Ali, a multiplicação é diretamente enunciada como operação que pode ser definida para os números naturais e que caracteriza a estrutura de $\mathbb{N}$. Na publicação $A$ Matemática Moderna no ensino primário, indicada como leitura para os alunos do curso, Dienes (1967, p.53) aborda a multiplicação considerando conjuntos de conjuntos: "Enquanto se efetua uma multiplicação muda-se de universo: [...]. Num produto um dos fatores pertence à família dos conjuntos, o outro à dos conjuntos de conjuntos".

Figura 6 - Definição da multiplicação de números naturais

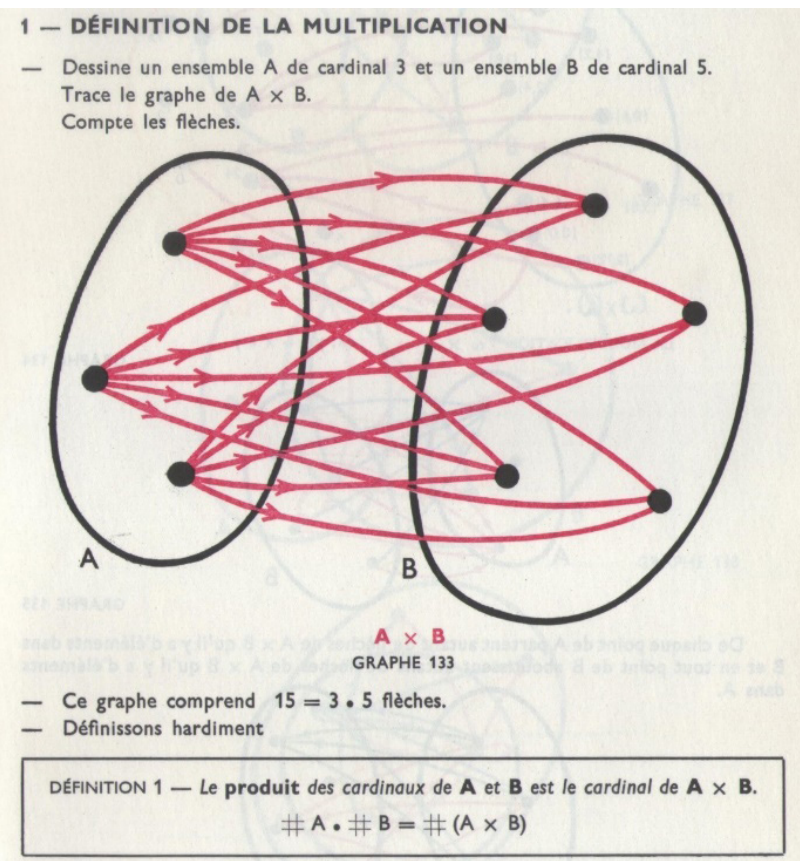

Fonte: Papy e Papy (1965, p. 271)

Finalmente, na coleção Mathématique moderne de Georges e Frédérique Papy ${ }^{12}$ (1965), encontramos uma

\footnotetext{
${ }^{11}$ Lucienne Félix foi professora de matemática do ensino secundário na França desde os anos 1920 até os anos 1960. Participou dos debates internacionais promovidos pela Comission Internationale pour l'Étude et l'Amélioration de l'Enseignement des Mathématiques (CIEAEM) desde 1950 e foi membro ativo da já mencionada APMEP. É autora de várias publicações dedicadas à modernização do ensino, para professores e estudantes de diferentes níveis, desde a pré-escola até o ensino superior. Esteve no Brasil em 1962, 1965 e 1968, ministrando palestras e realizando intercâmbio com educadores brasileiros (BÚRIGO, 2019).

${ }^{12}$ Georges Papy era professor da Universidade Livre de Bruxelas nos anos 1950, quando foi procurado por Willy Servais e Frédérique Lenger (mais tarde, Frédérique Papy) para um programa experimental de ensino de matemática para professores da pré-escola. Em 1961 criou o Centre Belge de Pédagogie de la Mathématique (CBPM), que congregava professores e autores de livros didáticos. Ao longo dos anos 1960 e 1970, o CBPM promoveu vários cursos, seminários e publicações sobre o ensino de matemática, recebendo educadores de diferentes países (VANPAEMEL, 2012).
} 
provável referência para a abordagem da multiplicação apresentada na apostila da disciplina "Fundamentação matemática". No primeiro volume da coleção, a multiplicação de números naturais é apresentada como um produto cartesiano. A Figura 6 mostra a definição apresentada no livro, que pode ser assim traduzida:

Desenhe um conjunto A de cardinal 3 e um conjunto $\mathrm{B}$ de cardinal 5. Trace o gráfico de $\mathrm{A} \times \mathrm{B}$. Conte as flechas. Esse gráfico contém $15=3 \cdot 5$ flechas. Definamos ousadamente: [...] o produto dos cardinais de A e B é o cardinal de A×B (PAPY; PAPY, 1965, p. 271, tradução e grifos nossos).

A partir de uma breve comparação entre as abordagens de diferentes autores, vemos que a apresentação da multiplicação como produto cartesiano, nas aulas de "Fundamentação Matemática", corresponde a uma escolha por parte de Esther Grossi, responsável pela disciplina. Um possível motivo para essa escolha é o grau de detalhamento e de rigor com que a matemática elementar é apresentada na coleção Papy, tomada como suporte para um empreendimento inovador. A participação de Georges Papy no 5 Congresso Brasileiro de Ensino de Matemática, em 1966, em São José dos Campos, é indicativa do seu prestígio no Brasil e do interesse dos educadores brasileiros no intercâmbio com o diretor do Centre Belge de Pédagogie de la Mathématique. Joana Bender que, conforme mencionado acima, era uma referência para as discussões e experiências de formação desenvolvidas no Instituto de Educação, foi uma das professoras brasileiras que estagiou no Centre após esse Congresso (MOTA, 2008). Uma outra explicação que pode ser aventada é que, ao estudar a abordagem de Papy e Papy (1965), Esther e outras professoras, alunas do Curso, poderiam ter entrevisto, ali, uma possibilidade interessante de didatização, ou de construção de uma situação didática, dando um novo sentido à multiplicação de números naturais.

\section{ENSINANDO A MULTIPLICAR COM SAIAS E BLUSAS}

A partir das considerações expostas acima, podemos pensar em saias e blusas como uma didatização da concepção de multiplicação como produto cartesiano. Ainda, é verossímil pensar que na atividade registrada no caderno de Cristiane Gross (1968) como continuidade (ou, talvez, como adaptação para uma sala de aula regular) da atividade de contagem dos trajes pela manipulação das figuras recortadas de saias e blusas com diferentes estampas.

Mas, não se trata de uma mera adaptação, concretização ou simplificação da ideia genérica de multiplicação como conjunto de pares ordenados, presente na coleção de Papy e Papy (1965) e na apostila do Curso de Didática da Matemática Moderna na Escola Primária. Há elementos próprios da matemática escolar na concepção dessa atividade de ensino que reúne elementos do universo infantil - roupas e cores -, introduz simbolismos modernos, como as flechas, e dá sentido à ideia de par ordenado - no caso, um possível traje.

Novamente, nos perguntamos sobre as inspirações para a criação da atividade, tomando como pressuposto que a ideia de produto cartesiano era objeto de estudo das professoras do curso primário do Instituto de Educação que frequentavam o Curso de Didática da Matemática Moderna na Escola Primária. Em conversa com Esther Grossi, durante a escrita deste texto - isto é, passados cinquenta anos da realização do Curso -, mostramos a fotografia que aparece na Figura 4. Ela, de imediato, mencionou que aquelas figuras faziam parte de um conjunto bem maior, e que as figuras eram usadas para que as crianças pudessem experimentar permutações. Lembrou, também, que Zoltan Dienes explorava, em diferentes atividades, o tema das permutações. Perguntamos se o material reproduzia produções já existentes ou era uma invenção da equipe envolvida no Curso e no Laboratório de Matemática do Instituto de Educação. Esther respondeu, sem certeza, que acreditava que aquela, como outras atividades envolvendo combinações de objetos, era uma criação local.

Encontramos saias e blusas, também, em uma publicação do final dos anos 1960: o segundo volume da coleção Curso moderno de Matemática para a escola elementar, da autoria de Manhúcia Perelberg Liberman, Anna Franchi e Lucilia Bechara ${ }^{13}$.

Figura 7 - Atividade para aprendizagem da multiplicação no segundo ano primário

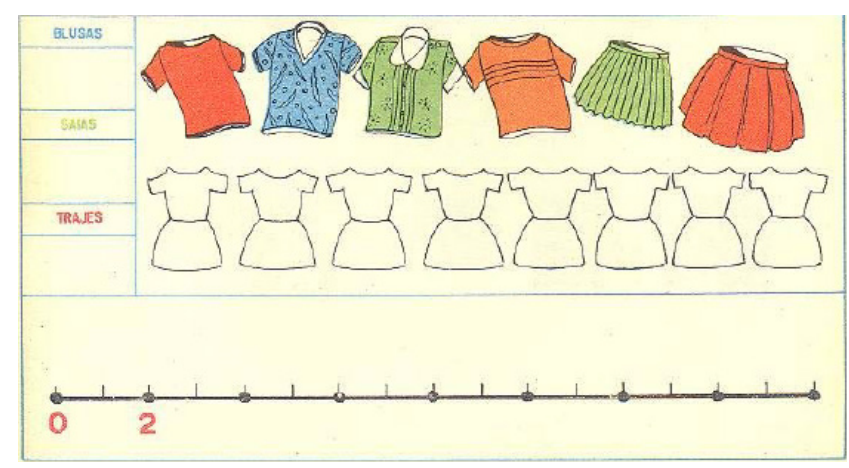

Fonte: Liberman, Franchi e Bechara (1967, p. 51)

A Figura 7 mostra uma atividade a ser realizada por estudantes do segundo ano do curso primário: a partir de uma imagem, as crianças deveriam obter os números

\footnotetext{
${ }^{13}$ Sobre as autoras e a coleção, ver Villela (2009).
} 
de saias, blusas e trajes. Saias e blusas são apenas um dentre muitos contextos que envolvem combinações, apresentados no livro: trajes de calça e camiseta, cores de olhos e cabelos de bonecas, composições de bebidas e comidas em uma merenda, escala de jogos em um campeonato de futebol, dentre outros. Consultamos Lucilia Bechara sobre a inspiração para essas atividades, mostrando também a Figura 1 do caderno de Cristiane Gross; ela nos respondeu que "Do que consigo lembrar, o trabalho com produto cartesiano (além da soma de parcelas iguais) na multiplicação surge na matemática moderna, particularmente com os franceses". Comentando a atividade do caderno, observou que "A utilização de flechas foi exaustivamente explorada por George Papy da Bélgica e em Luxemburgo como se pode ver nos escritos por Robert Dieshbourg". Poderíamos ainda nos perguntar se a imagem da coleção Curso moderno de Matemática para a escola elementar teria sido inspiradora da atividade realizada no IE; mas isso é improvável pois a multiplicação, na coleção, não é obtida pela contagem das flechas (ou pares ordenados), mas pela repetição de um deslocamento de duas unidades, como mostra a Figura 7.

Em uma discussão sobre memória e história, Nora (1993, p.9) aponta que "A memória se enraíza no concreto, no espaço, no gesto, na imagem, no objeto". Nunes (2003, p. 15) fala do caráter "compósito e flexível" da memória dos indivíduos:

As memórias estão relacionadas a processos de subjetivação bastante complexos, que incluem desde sensações e imagens mentais altamente espontâneas até solenes cerimônias públicas vividas intensamente. Elas estão ancoradas em espaços e lugares nos quais circulamos, em grupos sociais de diferentes tipos aos quais pertencemos, em objetos que manipulamos. Quem recorda são os indivíduos, e essa experiência de caráter singular está presente quando se enfatiza a memória social, pois os indivíduos não são autômatos, passivos e obedientes a uma vontade social interiorizada.

Mostramos o registro do caderno (Figura 1) à sua autora e usuária: Cristiane Gross não tinha uma recordação particular daquela atividade realizada no segundo ano primário. Para os alunos, era mais uma tarefa escolar. Já para Esther Grossi e Lucilia Bechara, as imagens evocaram, de imediato, um tempo em que estavam mobilizadas para renovar o ensino de matemática na escola primária. Esther mencionou a influência de Dienes, e Lucilia, mencionou, além de Papy, “os franceses". Em um livro da educadora francesa Nicole Picard constante do acervo do LM/IE, encontramos a recomendação da exploração da combinatória "desde a pré-escola" (PICARD, 1970, p. 68), seguida de alguns exemplos de atividades envolvendo objetos. Como referências, a autora menciona a coleção dos Papy, livros de Zoltan Dienes e uma publicação de Guy Brousseau, dentre outros. Entretanto, o intercâmbio de Esther Grossi com Nicole Picard e Dienes é posterior ao registro do caderno e ao início do Curso; o mais provável é que essas referências, amalgamadas nas reminiscências daqueles tempos, não tenham participado da elaboração da atividade com saias e blusas.

Ao mesmo tempo, e por outro lado, a evocação de diferentes autores e interlocutores nos faz pensar na Matemática Moderna como um movimento vivo, em que autores e professores engajados em experimentações ou inovações dialogavam por meio de encontros e publicações, por sua vez impregnadas por esse debate multifacetado. A concepção da multiplicação como produto cartesiano não se esgotava na definição e nas icônicas ilustrações da coleção dos Papy; a abordagem do que hoje denominamos pensamento combinatório, desde a escola elementar, foi uma das muitas proposições inovadoras do movimento da Matemática Moderna, enunciada por diferentes autores e em diferentes versões.

\section{SAIAS E BLUSAS NO CURRÍculo PRATICADO DE UMA ESCOLA PRIMÁRIA}

No caderno de Cristiane Gross (1968), o "Trabalho de Matemática", envolvendo combinações de saias e blusas, e automóveis e latas de tinta, não é o primeiro registro de atividade envolvendo a multiplicação. $O$ registro anterior, do dia 6 de agosto, é o de uma lista de exercícios de multiplicação com números de um algarismo, como $4 \times 3$ e $2 \times 5$, precedidos da instrução "Arma e resolve estas multiplicações". O registro seguinte ao "Trabalho de Matemática", do dia 12 de agosto, apresenta uma sequência de perguntas e respostas sobre a multiplicação. No primeiro item, a pergunta "O que é multiplicação?" é respondida com "Multiplicação é o nome de uma operação de adicionar"; o terceiro item pede o preenchimento de lacunas em uma frase, cuja escrita final é "Quando multiplicamos reunimos quantidades iguais". A anotação "Excelente!", na margem do caderno, nos leva a pensar que as respostas dadas pela aluna eram as esperadas, ou semelhantes às esperadas pela professora.

Pelos registros da estudante, então, vemos que a ideia da multiplicação como soma de parcelas iguais não foi abandonada naquela série, por aquela professora. Além disso, o "Trabalho de Matemática" é a única atividade constante no caderno envolvendo combinações de elementos de conjuntos distintos.

O currículo praticado naquela turma, portanto, não estava orientado por um programa amplamente reformulado ou pretensamente inovador. $\mathrm{O}$ "Trabalho 
de Matemática" pode ser considerado um traço de uma experimentação pontual de uma inovação, em que a multiplicação é abordada por meio de um problema combinatório e de uma representação gráfica. Conforme anteriormente comentado, essa experimentação poderia ter sido realizada pela iniciativa de uma estagiária normalista, pela professora da turma ou por colegas participantes do Curso de Didática.

O caráter localizado da inovação é, em parte, explicado pelos obstáculos à introdução de novos conteúdos e terminologias no curso primário, mencionados na já referida ata de 16 de março de 1967:

Qual será nossa posição para iniciar o trabalho? Não temos experiência e o campo aberto é apenas o Jardim de Infância, onde o trabalho é feito em forma de jogo e sem maior interferência da família. A melhor tentativa seria em classes de experimentação, porque é preciso enfrentar muitas dificuldades: com a administração, em tomar a responsabilidade da experiência; com os professores, pela falta de preparo, e com a comunidade, a maior delas, face à sua estruturação rígida (Item 1316 do Acervo do LM/IE, p. 1).

Podemos perceber essa experimentação pontual, também, à luz das discussões mais recentes sobre o currículo no cotidiano escolar, que apontam o caráter sempre complexo e contraditório das práticas curriculares:

[...] em nossas atividades cotidianas, os currículos que criamos misturam elementos das propostas formais e organizadas com as possibilidades que temos de implantá-las e o acordo ou desacordo que temos sobre elas. Por sua vez, essas possibilidades se relacionam com aquilo que sabemos e em que acreditamos, ao mesmo tempo que são definidas na dinâmica de cada turma, dos saberes dos alunos, das circunstâncias de cada dia de trabalho. [...] É nesse sentido que entendemos as práticas curriculares cotidianas como 'multicoloridas', pois suas tonalidades vão depender sempre das possibilidades daqueles que as fazem e das circunstâncias nas quais estão envolvidos (ALVES; OLIVEIRA, 2002, p.96-97).

Assim como outros registros do caderno, saias e blusas podem ser consideradas traços da Matemática Moderna em meio a essas práticas "multicoloridas" experimentadas pelas estudantes e professoras do Instituto de Educação, naqueles idos anos 1960. Não se tratava de aplicar um programa pré-estabelecido, ou de replicar as orientações de um livro didático, mas de ensinar a multiplicar, usando materiais existentes e criando novos.

Considerando as conexões apontadas entre os registros do caderno, os materiais encontrados no acervo do LM/IE e a coleção dos Papy, poderíamos pensar em saias e blusas - e automóveis e latas de tinta - como uma apropriação da ideia de produto cartesiano pelas professoras e estudantes do Instituto de Educação, entendendo apropriação "como uso particular de um sistema, uso cujo modelo é a enunciação, ou como tática, por oposição à estratégia" (NUNES; CARVALHO, 2005, p. 53).

Mais elucidativo, talvez, do que a ideia de apropriação, é pensarmos em saias e blusas como criação própria da cultura escolar. Como argumenta Chervel (1990, p. 184), "o sistema escolar é detentor de um poder criativo insuficientemente valorizado até aqui”. As criações do sistema escolar são orientadas pelas finalidades próprias da escola - como o ensino das operações aritméticas - e pelas condições em que se realizam as práticas escolares. Nessa perspectiva, ao invés de pensar que a escola se ocupou em incorporar a ideia de produto cartesiano como mais um conceito da Teoria dos Conjuntos a ser escolarizado e didatizado, podemos cogitar que a ideia de produto cartesiano foi introduzida na escola como componente da criação da atividade com saias e blusas - e outros objetos representáveis por figuras -, que permitiriam aos alunos experimentar e atribuir novos sentidos à multiplicação.

\section{SAIAS E BLUSAS COMO RESSONÂNCIAS DA MATEMÁtica Moderna}

A linguagem e o simbolismo da Teoria dos Conjuntos foram, possivelmente, os elementos mais difundidos da Matemática Moderna. Algumas representações de que a Matemática Moderna teria fracassado ou teria sido descartada, a partir dos anos 1980, estão apoiadas na verificação de que livros didáticos e outros materiais foram, progressivamente, abandonando esses elementos de linguagem. Considerando a autonomia dos Estados para definirem as suas diretrizes curriculares, e os ritmos muito variados com que essas diretrizes foram atualizadas, ao longo dos anos 1970 e 1980, é difícil identificar em que medida essas mudanças nos livros responderam às alterações de documentos legais, a demandas das comunidades escolares ou outros tipos de movimentações.

Ao final dos anos 1960, a ideia de multiplicação como produto cartesiano havia sido introduzida em obras para o ginásio, como a já mencionada coleção de Sangiorgi (1968) ou a coleção Ensino moderno da Matemática elaborada pelo Núcleo de Estudo e Difusão do Ensino da Matemática (NEDEM, 1967). No manual pedagógico Matemática, metodologia e complementos para professores primários, de Ruy Madsen Barbosa (1966), a multiplicação também é definida a partir do conceito de produto cartesiano.

A linguagem dos conjuntos, conforme comentado acima, foi progressivamente descartada pelos autores 
de livros didáticos e pelos redatores dos documentos de orientação curricular. Entretanto, a ideia de multiplicação como produto cartesiano está presente nos Parâmetros Curriculares Nacionais para os anos iniciais do Ensino Fundamental. Mais interessante ainda é perceber que a ideia é ilustrada por um problema de combinações possíveis entre saias e blusas: "Tendo duas saias — uma preta $(\mathrm{P})$ e uma branca $(\mathrm{B})$ - e três blusas - uma rosa (R), uma azul (A) e uma cinza (C) - , de quantas maneiras diferentes posso me vestir?" (BRASIL, 1997, p. 73). Pela Figura 8, vemos algumas das soluções esperadas para esse problema.

Figura 8 - Soluções sugeridas para o problema das combinações de saias e blusas

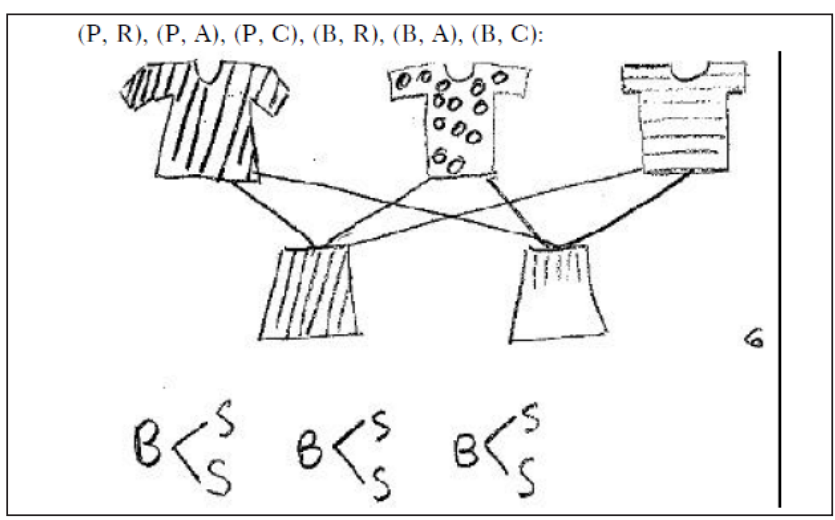

Fonte: Brasil (1997, p. 73).

Na solução da Figura 8, podemos identificar vestígios do que teria sido uma solução dos anos 1960. As saias e blusas reaparecem com novos estilos e estampas; as flechas são substituídas por elos de ligação; os pares ordenados são listados, mas não aparecem entre chaves, de modo que a ideia de conjunto fica sugerida, mas não explicitada.

Considerando que os Parâmetros Curriculares Nacionais foram tomados, desde a sua publicação, como referência para a avaliação de livros didáticos, prosseguimos a investigação. Encontramos saias e blusas em uma coleção didática autorizada e distribuída pelo Programa Nacional do Livro Didático para o triênio 20162018 (BONJORNO et al., 2016). E, provavelmente, uma busca mais minuciosa permitiria identificar outros rastros nos livros didáticos atualmente em uso.

Podemos pensar, então, em saias e blusas como uma marca permanente daquele movimento de inovação curricular que emergiu no Brasil nos anos 1960. A valorização do pensamento combinatório em crianças e a associação entre multiplicação e produto cartesiano podem ser considerados legados do movimento da matemática moderna.

\section{CONSIDERAÇÕES FINAIS}

A investigação apresentada neste artigo não foi organizada a partir de uma questão abrangente sobre os impactos do Curso de Didática no ensino de matemática praticado no curso primário do Instituto de Educação, ou acerca do alcance e da permanência das experimentações ali realizadas, ao tempo da Matemática Moderna. A pesquisa foi provocada por indícios que encontramos durante o trabalho simultâneo com dois acervos, e possibilitou identificar múltiplas conexões entre os esforços de renovação do ensino de matemática, nos anos 1960, em diferentes cursos da mesma instituição e em diferentes partes do país e do mundo.

A investigação indica, ainda, que aquela inovação não foi introduzida como componente de uma grande mudança curricular, mas como uma experimentação criativa e localizada de uma nova abordagem de uma operação aritmética. A persistência de uma abordagem muito assemelhada em documentos recentes sugere que a ideia era didaticamente poderosa, ao mesmo tempo em que revela uma tendência à reprodução de exercícios e contextos, ao longo do tempo. Pois, nos anos 2010, saia e blusa não é um traje comum e emblemático como era nos anos 1960 .

Os achados também contribuem para a desmitificação e a desmistificação da ideia de que a Matemática Moderna teria sido uma imposição dos governos ou dos matemáticos. No Instituto de Educação, como em muitas outras partes, professores se mobilizaram para estudar, inventar e ensinar.

A preservação de acervos escolares, que está na origem da escrita deste texto, possibilitará que muitas outras investigações sejam realizadas, ampliando a rede de conexões entre os indícios e a nossa compreensão sobre as mudanças e as permanências nos currículos escolares.

\section{REFERÊNCIAS}

ALBUQUERQUE, I. Metodologia da matemática. Rio de Janeiro: Conquista, 1951.

ALVES, N.; OLIVEIRA, I. B. Uma história da contribuição dos estudos do cotidiano escolar ao campo do currículo. In: LOPES, A. C.; MACEDO, E. (Orgs.). Currículo: debates contemporâneos. São Paulo: Cortez, 2002. p. 78-102.

BARBOSA, R. M. Matemática, metodologia e complementos para professores primários. Aritmética teórico-prática. v. 1. São Paulo: LPM, 1966.

BONFADA, E. M. A matemática na formação das professoras normalistas: o Instituto de Educação General Flores da Cunha em tempos de matemática moderna. 2018. Dissertação (Mestrado em Ensino de Matemática) - Universidade Federal do Rio Grande do Sul, Porto Alegre, 2018. 
BONJORNO, J. R.; AZENHA, R.; GUSMÃO, T.; RIBEIRO, M. Malabares: alfabetização matemática. São Paulo: FTD, 2016 .

BRASIL. Ministério da Educação. Secretaria de Educação Fundamental. Parâmetros Curriculares Nacionais: Matemática. Brasília: MEC/SEF, 1997. Disponível em: http:// portal.mec.gov.br/seb/arquivos /pdf/livro03.pdf. Acesso em: 30 mar. 2019.

BÚRIGO, E. Z. A Matemática Moderna na UFRGS: o protagonismo dos professores da universidade. In: FLORES, C.; ARRUDA, J. P. (org.). A matemática moderna nas escolas do Brasil e Portugal. São Paulo: Annablume, 2010. p. 89-116.

BÚRIGO, E. Z. Exposé moderne des mathématiques élémentaires: quando uma obra precede sua autora. Zetetiké, Campinas, n. 27, p. 1-16, 2019. https://doi.org/10.20396/zet. v27i0.8654365

BÚRIGO, E. Z.; PEIXOTO, F. A. B. Aprender a ensinar: memórias de professoras normalistas. Educação Matemática em Revista-RS, Porto Alegre, v. 2, n. 19, p. 21-33, 2018.

CHERVEL, A. História das disciplinas escolares: reflexões sobre um campo de pesquisa. Teoria \& Educação, Porto Alegre, n. 2, p. 177-229, 1990.

COLMEZ, F.; HOSSON, C.; PICHAUD, J; ROBERT, A. (org.). Hommage à André Revuz. Paris: Laboratoire de Didactique André Revuz, 2010. Disponível em: https://ocs. wixstatic.com/ugd/d9da21 7e379b811a40425e89fdb71c0415 34dd.pdf. Acesso em: 31 mar. 2019.

DALCIN, A.; BONFADA, E. M.; RHEINHEIMER, J. M. Odila Barros Xavier e o ensino de matemática: percursos de uma professora formadora. Educação Matemática em Revista, Brasília, v. 2, n. 19, p. 9-20, 2018.

D'AMBROSIO, B. S. The dynamics and consequences of the modern mathematics reform movement for brazilian mathematics education. 1987. Tese (Doctor of Philosophy) - School of Education, Indiana University, Bloomington, 1987.

D'AMBROSIO, B. S. Dinâmica e as consequências do movimento da matemática moderna na educação matemática do Brasil. Campinas: Mercado de Letras, 2017.

DIENES, Z. P. A matemática moderna no ensino primário. Rio de Janeiro/São Paulo: Horizonte/Fundo de Cultura, 1967.

FÉLIX, L. Mathématiques modernes $\cap$ enseignement élémentaire. Paris: Albert Blanchard, 1960.

FISCHER, M. C. B. A experiência das classes piloto organizadas pelo GEEMPA, ao tempo da Matemática Moderna. Revista Diálogo Educacional, PUC-PR, Curitiba, v. 6, n. 18, p. 101-112, maio/ago. 2006. https://doi. org/10.7213/rde.v6i18.3319
GEEM. Grupo de Estudos em Ensino de Matemática. Matemática moderna para o ensino secundário. São Paulo: IBECC, 1962.

GROSS, Cristiane. Diário de aulas. Porto Alegre: 1968. Caderno escolar utilizado no segundo ano do curso primário. Disponível em: https://repositorio.ufsc.br/handle /123456789/186985. Acesso em: 30 mar. 2019.

GROSS, Cristiane. Entrevista concedida a Nicolas Giovani da Rosa, em 3 de setembro de 2018. Não publicada.

GROSSI, E. P. Uma arqueologia dos saberes do GEEMPA. Revista GEEMPA (35 anos), Porto Alegre, n. 10, p. 11-39, set. 2005.

KLINE, M. O fracasso da matemática moderna. Tradução: Leonidas Gontijo de Carvalho. São Paulo: Ibrasa, 1976.

LEME DA SILVA, M. C.; VALENTE, W. R. Na oficina do historiador da educação matemática: cadernos de alunos como fontes de pesquisa. Belém: SBHMat, 2009. Coleção História da Matemática para Professores. v. 19. Disponível em: http:/www2.unifesp.br/centros/ghemat/images/stuffs/ OFICINA_Parte_1.pdf. Acesso em: 31 mar. 2019.

LEME DA SILVA, M. C.; VALENTE, W. R. Uma breve história do ensinar e aprender matemática nos anos iniciais: uma contribuição para a formação professores. Educação matemática e pesquisa, São Paulo, v. 15, n. especial, p. $857-871,2013$.

LIBERMAN, M. P.; FRANCHI, A.; BECHARA, L. Curso moderno de Matemática para a escola elementar. v. 2. São Paulo: Companhia Editora Nacional, 1967.

MOTA, Telmo Pires. Entrevista concedida a Elisabete Búrigo. Porto Alegre: janeiro de 2008. Não publicada.

NEDEM. Núcleo de Estudo e Difusão do Ensino da Matemática. Ensino Moderno da Matemática. v. 1. São Paulo: Editora do Brasil, 1967.

NORA, P. Entre memória e história: a problemática dos lugares. Tradução de Yara Aun Khoury. Revista do Programa de Estudos Pós-Graduados em História e do Departamento de História da PUC-SP, Projeto História, São Paulo, n.10, p. 7-28, dez.1993.

NUNES, C. Memória e história da educação: entre práticas e representações. In: LEAL, M. C.; PIMENTEL, M. A. L. (org.). História e memória da Escola Nova. São Paulo: Loyola, 2003. p. 9-25.

NUNES, C.; CARVALHO, M. M. C. Historiografia da educação e fontes. In: GONDRA, J. G. (org.). Pesquisa em história da educação no Brasil. Rio de Janeiro: DP \& A, 2005. p. 17-62.

OLIVEIRA, M. A. A aritmética escolar e o método intuitivo: um novo saber para o curso primário (1870-1920). 2017. Tese de Doutorado (Programa de Pós-Graduação em Educação e Saúde na Infância e na Adolescência) Universidade Federal de São Paulo, São Paulo, 2017. 
OLIVEIRA, M. C. A.; LEME DA SILVA, M. C.; VALENTE, W. R. (org.). O Movimento da Matemática Moderna: história de uma revolução curricular. Juiz de Fora: Editora da UFJF, 2011.

PAPY, G.; PAPY, F. Mathématique moderne. v. 1. Bruxelles: Didier, 1965.

PICARD, N. Des ensembles à la découverte du nombre. Paris: OCDL, 1970.

REVUZ, A. Mathématique moderne, mathématique vivante. Paris: OCDL, 1963.

RIO GRANDE DO SUL. Decreto no ${ }^{\circ} 6004$, de 26 de Janeiro de 1955. In: RIO GRANDE DO SUL. Coletânea legislativa, decretos estaduais de 1955. Porto Alegre: 1955. p. 91-103.

SANCHEZ, L. B. Prefácio. In: LEME DA SILVA, M. C.; VALENTE, W. R. Na oficina do historiador da educação matemática: cadernos de alunos como fontes de pesquisa. Belém: SBHMat, 2009.

SANGIORGI, O. Matemática: curso moderno para cursos ginasiais. v. 1. São Paulo: Companhia Editora Nacional, 1964.

SANGIORGI, O. Matemática: curso moderno. Volume 1 para os ginásios. Guia para uso dos professores. São Paulo: Companhia Editora Nacional, 1968.

THOFEHRN, C. C.; CUNHA, N. Estrada iluminada. A festa do vaga-lume. v. 2. São Paulo: Editora Brasil, 1968.

TRAJANO, A. Arithmetica elementar illustrada. Rio de Janeiro: Martins de Araujo, [190-?].

VALENTE, W. R. O que é número? Produção, circulação e apropriação da Matemática Moderna para crianças. Bolema, Rio Claro, v. 26, n. 44, p. 1417-1442, 2012. https://doi. org/10.1590/S0103-636X2012000400014

VANPAEMEL, G. Belgian contributions to the New Math movement in Europe. The role of international organizations and the influence of the periphery. STEP MEETING, 8., 2012, Corfu. Anais [...]. Corfu, 2012. p. 1-11. Disponível em: https://www.researchgate.net/profile/Geert_Vanpaemel/ publication/. Acesso em: 31 mar. 2019.

VILLELA, L. M. A. "GRUEMA": uma contribuição para a História da Educação Matemática no Brasil. 2009. Tese (Doutorado em Educação Matemática) - Universidade Bandeirante de São Paulo, São Paulo, 2009.

VIÑAO, A. Os cadernos escolares como fonte histórica: aspectos metodológicos e historiográficos. In: MIGNOT, A. C. V. (ed.). Cadernos à vista: escola, memória e cultura escrita. Rio de Janeiro: EdUERJ, 2008. p. 15-33.
Endereço para correspondência:

Elisabete Zardo Búrigo

Universidade Federal do Rio Grande do Sul

Av. Bento Gonçalves, 9500

91501-970, Porto Alegre, RS, Brasil

\section{Autores:}

ELISABETE ZARDO BÚRIGO

Doutora em Educação pela Universidade de São Paulo (USP), São Paulo, SP. Licenciada em Matemática pela Universidade Federal do Rio Grande do Sul (UFRGS), Porto Alegre, RS. Docente na Universidade Federal do Rio Grande do Sul, Porto Alegre, RS, Brasil.

Orcid: http://orcid.org/0000-0003-1532-7586

E-mail: elisabete.ufrgs@br

Nícolas Giovani Da Rosa

Licenciando em Matemática na Universidade Federal do Rio Grande do Sul (UFRGS), Porto Alegre, RS, Brasil. Bolsista de Iniciação Científica. Orcid: http://orcid.org/0000-0002-2794-5747

E-mail: nicolasgiovani20@gmail.com

Mayara Becker Oliveira da Silva

Licencianda em Matemática na Universidade Federal do Rio Grande do Sul UFRGS, Porto Alegre, RS, Brasil. Bolsista de Iniciação Científica.

Orcid: http://orcid.org/0000-0002-2693-0201

E-mail: mayarabeckeros@gmail.com 